\title{
Functional Health Literacy and Doctor-Patient Communication: Experiences of HIV/AIDS Patients in Homa Bay County, Kenya
}

\author{
Dennis Butto ${ }^{1,2 *}$, Hellen Mberia1, Julius Bosire ${ }^{3}$ \\ ${ }^{1}$ School of Communication and Development Studies, Jomo Kenyatta University of Agriculture and Technology, Nairobi, Kenya \\ ${ }^{2}$ School of Health Sciences, Kirinyaga University, Kerugoya, Kenya \\ ${ }^{3}$ Technical University of Kenya, Nairobi, Kenya \\ Email: *dbutto@kyu.ac.ke
}

How to cite this paper: Butto, D., Mberia, H. and Bosire, J. (2020) Functional Health Literacy and Doctor-Patient Communication: Experiences of HIV/AIDS Patients in Homa Bay County, Kenya. Journal of Biosciences and Medicines, 8, 43-57.

https://doi.org/10.4236/jbm.2020.812005

Received: October 22, 2020

Accepted: December 11, 2020

Published: December 14, 2020

Copyright $\odot 2020$ by author(s) and Scientific Research Publishing Inc. This work is licensed under the Creative Commons Attribution International License (CC BY 4.0).

http://creativecommons.org/licenses/by/4.0/

\begin{abstract}
Patient involvement in the health care process has been documented as a critical component of successful disease management. However, inadequate functional health literacy among patients is a well-known barrier to effective doctor-patient communication, which has an adverse effect on health outcomes. This study aimed at investigating the association of functional health literacy and doctor-patient communication among HIV/AIDS patients in Homa Bay County, Kenya. It was a cross-sectional hospital-based survey conducted among 362 HIV/AIDS patients receiving care at the eight sub-county hospitals of Homa Bay county. Data was collected using a self-administered structured questionnaire. Cronbach's alpha and confirmatory factor analysis tests were used to ascertain the reliability and validity of study instruments, while Logistic regression logistic analysis was used to measure the association between functional health literacy and doctor-patient communication. $51 \%$ of the respondents were females, and the majority (30.9\%) of respondents fell in the age group of 45 years and above. The respondents' functional health literacy levels were inadequate at weighted means scores of 3.23 [SD 1.31]. The study further established that functional health literacy significantly influenced doctor-patient communication [Nagelkerke $\mathrm{R}$ square $=0.318$ ]. There is, therefore, a need to document the determinants of functional health literacy to improve it and make doctor-patient interaction an enjoyable and meaningful experience.
\end{abstract}

\section{Keywords}

Doctor-Patient Communication, HIV/AIDS, Functional Health Literacy 


\section{Introduction}

Literacy is acquired through the process of learning to read and write. Then again, functional literacy is characterized by the reading and writing abilities and information that empower a person to be involved in the specific activities of the area that requires this contribution [1]. Applying this idea to the field of health, functional health literacy can be depicted as the cognitive capacity to comprehend, interpret and apply written or oral health information so that someone with a great literacy level would have a better health condition than one with a limited literacy level, who would be less cognizant of the significance of preventive practices, for instance, or problems in understanding guidelines on medication [2]. Therefore, this has placed functional health literacy at the center of interest among researchers, health experts, and public policy-consultants involved in health promotion as several studies have given evidence of people's low functional health literacy [3]. Although the exact level of health literacy is unknown in Kenya, it's expected to be low going by studies from other regions. For instance, in the North American population, 9 out of every ten adults lack requisite competency to manage their health and prevent diseases [3]. Previous studies show that in the United Kingdom, the United States, Australia, and Canada, from twenty to fifty percent of the population have low functional health literacy, which can negatively affect an individual's health status [4] [5] [6].

Over the past decade, scholars have come up with various tools to measure health literacy. The Rapid Estimate of Adult Literacy in Medicine (REALM) and the Test of Functional Health Literacy in Adults (TOFHLA) are the most widely recognized and approved measures of functional health literacy [7]. The REALM tests word recognition, while the TOFHLA tests how well a person can interpret what is read and the meaning of numbers presented to them [2]. A brief version of the TOFHLA, the S-TOFHLA contains fewer questions, simpler to administer, and compares well to the TOFHLA in its consistency. It utilizes an adjusted cloze methodology where an individual reads a health-related passage in which every $5^{\text {th }}$ to $7^{\text {th }}$ word is omitted, and the right word is selected [8]. The other tool, known as "the Newest Vital Sign" is a general evaluation of health literacy which lasts only three minutes, is easy to apply, and is comparable to more compressive evaluations of health literacy like REALM and the S-TOFHLA but it is, however, isn't always related with health outcomes [9].

Ishikawa et al. [6] advanced a self-reported health literacy scale, which is in line with Nutbeam's version. Unlike other health literacy measurement tools, this scale, which measures all three levels, seems to be a promising tool for estimating the full range of health literacy. The functional, communicative, and critical health literacy scales are not complicated and easy to apply and have been validated for use as a screening tool in research settings [10]. The level of functional health literacy is not known in Kenya; neither has any health literacy measurement scale that takes into account the local context been developed. This study used the seven items measure of functional health literacy developed 
by Chew et al. and adopted from An \& Muturi [11] to measure functional health literacy among the study respondents.

\section{Methods}

\subsection{Study Design}

This was a cross-sectional, quantitative survey design conducted among 384 HIV/AIDS patients in Homa Bay county.

\subsection{Sampling Technique}

A stratified random sampling method was applied to select the respondents in the eight hospitals in Homa county or the eight strata for this study, as shown in Table 1 .

\subsection{Data Collection Instrument}

This study used a structured self-administered questionnaire to obtain data from the respondents. The seven items measure of functional health literacy developed by Chew et al. and adopted from An \& Muturi [11] and fifteen questions adapted from the Consumer Assessment of Healthcare Providers and Systems [CAHPS] health literacy item set were used to measure functional health literacy and doctor-patient communication respectively among the study respondents. The CAHPS health literacy item set is a validated tool developed to assess provider communication about medicines, tests, and medical conditions. The study adopted the five response categories standard for CAHPS ["never," "rarely," "occasionally," "regularly" and "always"]. For all but 2 of the CAHPS questions, "always" represented the most positive response, but for the questions that asked about providers using medical jargon and speaking too fast, the "never" response was the most favorable. Thus, the coding for this question was reversed to be consistent with the other CAHPS questions. A weighted mean score was calculated for each CAHPS survey collected, with possible scores ranging from 1

Table 1. Strata and sampling intervals for the study.

\begin{tabular}{cccc}
\hline Hospital & Clients population & Stratified sample & Sampling Interval \\
\hline $\begin{array}{c}\text { Homa Bay } \\
\text { County Referral }\end{array}$ & 7214 & 166 & 43 \\
Mbita sub-county & 3226 & 74 & 44 \\
Suba sub-county & 2232 & 54 & 41 \\
Rangwe sub-county & 554 & 13 & 43 \\
Ndhiwa sub-county & 328 & 8 & 41 \\
Karachuonyo & 873 & 20 & 44 \\
sub-county & & 26 & 38 \\
Kasipul sub-county & 975 & 27 & 45 \\
Kabondo sub-county & 1223 & 384 & \\
Total & 16,625 & & \\
\hline
\end{tabular}


[lowest rating of provider communication] to 5 [highest possible provider communication rating].

\subsection{Data Collection Procedure}

The prospective respondents were obtained from the sampling frame and sampled using the sampling intervals, as indicated in Table 1 above, randomly starting from the first name on the list. The clinic appointment dates for selected patients were then noted, and clients who were not very ill approached at the registration department of the clinic where their consent was sought and questionnaires issued to those who consented. The questionnaires were picked from respondents after they had completed the treatment process. This process will be repeated until the 384 questionnaires were distributed. In the end, only 362 were filled up and included in the final analysis giving a response rate of $94 \%$.

\subsection{Validity and Reliability of the Study Instrument}

Thirty (30) participants drawn from HIV/AIDS patients in the neighboring Migori County participated in the pilot study. Additionally, factor analysis and Cronbach's Alpha test were used to determine the study instrument's validity and reliability, respectively. The alpha coefficient for variables constituting doctor-patient communications and functional health literacy were above the recommended threshold of 0.7 .

\subsection{Ethical Consideration}

The researchers obtained a permit from the National Commission for Science, Technology, and Innovation-Kenya. In Homa Bay county, the county director for health and the chief executive officer, Homa Bay County Teaching and Referral Hospital, granted the study's authority. Informed consent was obtained from each participant. All participants were assured of anonymity and confidentiality and were informed of the purpose, the procedures, risk, benefits, and voluntary participation. This information was reinforced with an informed consent form whose content was verbally presented to each participant. No personal identifying information was included in the tool or report to ensure further confidentiality, and participants were informed that their involvement or lack of it would not affect their care at the clinic.

\section{Results and Discussion}

\subsection{Demographic Characteristics}

The respondents' demographic characteristics included: age, gender, marital status, and education level. The respondents were also asked to state that they were first diagnosed with HIV infection from which illness duration was calculated. The results are illustrated in Table 2.

The respondents' age distribution was between 18 years and 69 years, with the majority [31\%] aged above 45 years followed by 25 - 31 years [21\%], while young 
Table 2. Patients demographic characteristics and effectiveness of doctor-patient communication.

\begin{tabular}{|c|c|c|}
\hline Demographic Factors $n=362$ & Frequency & $\%$ Percentage \\
\hline \multicolumn{3}{|c|}{ Age of the respondents } \\
\hline 18 - 24 years & 57 & 15.7 \\
\hline $25-31$ years & 67 & 18.5 \\
\hline $32-38$ years & 54 & 14.9 \\
\hline 39 - 45 years & 72 & 19.9 \\
\hline Above 45 years & 112 & 30.9 \\
\hline Total & 362 & 100.0 \\
\hline \multicolumn{3}{|c|}{ Marital status } \\
\hline Married & 189 & 52.2 \\
\hline Divorced & 29 & 8.0 \\
\hline Widowed & 54 & 14.9 \\
\hline Single & 90 & 24.9 \\
\hline Total & 362 & 100.0 \\
\hline \multicolumn{3}{|c|}{ Level of education } \\
\hline Class 8 or less & 100 & 27.6 \\
\hline Some High School & 118 & 32.6 \\
\hline High school completed & 93 & 25.7 \\
\hline College/University & 51 & 14.1 \\
\hline Total & 362 & 100.0 \\
\hline \multicolumn{3}{|c|}{ Duration of HIV infection } \\
\hline $0-5$ years & 67 & 18.5 \\
\hline $6-10$ years & 107 & 29.6 \\
\hline 11 - 15 years & 91 & 25.1 \\
\hline $16-20$ years & 71 & 19.6 \\
\hline 21 years and above & 26 & 7.2 \\
\hline Total & 362 & 100.0 \\
\hline
\end{tabular}

people aged between 18 - 24 years made up $16 \%$ of the respondents as illustrated in Table 2. Regarding the respondent's marital status, the majority [52\%] were married, $25 \%$ single, while $15 \%$ and $8 \%$ were widowed and divorced. The respondents were asked to state the gender with which they identify themselves, and the option of male, female, or others was given. One hundred eighty-four accounting for $51.05 \%$, were female while 48.69 were male, and a further $0.26 \%$ choose "others" without giving further details, as illustrated in Table 2. The above results illustrate that there was almost parity in terms of the gender of the respondents, even though the female gender was a slight majority. This agrees with the previous studies on HIV/AIDS prevalence in Homa Bay county, where women had significantly higher HIV prevalence than men at $6.9 \%$ compared to 4.4\%; $P<0.0001$ [12] [13]. These results contrasted other previous studies that 
found HIV prevalence to be highest among persons who had been widowed or formally married, separated, or divorced, probably due to the loss of the absent spouse to HIV/AIDS [14]. The finding herein gives hope that with good adherence to HIV/AIDS lifesaving drugs and good self-management skills, a patient can normally live if their partner dies of HIV/AIDS. As shown in Table $257 \%$ of the respondents had post-primary school education, even though $31 \%$ did not finish high school. $28 \%$ were educated up to class eight, while $14 \%$ were college or university graduates. Table 2 shows that the majority [30\%] of the respondents were those who had been having HIV/AIDS infection for between 6 - 10 years, followed by $25 \%$ who had been with the infection for between $11-15$ years while $19 \%$ and $7 \%$ had had the infection for between $0-5$ years and 21 years above, respectively. The fact that over $50 \%$ of respondents had lived with HIV infection for more than ten years could be a pointer to the efficacy of preventive and supportive measures put in place by the government.

\subsection{Functional Health Literacy}

As illustrated in Table 3, functional health literacy [FHL] among HIV/AIDS patients was measured using the seven [7] items scale developed by Chew et al. and adopted by An \& Muturi [11]. The respondents were asked to respond to the seven items using a Likert scale ranging from never [1] to always [5], always

Table 3. Distribution of respondents by responses to functional health literacy items.

\begin{tabular}{|c|c|c|c|c|c|c|c|c|}
\hline \multicolumn{2}{|r|}{ Functional Health Literacy Items $\mathrm{N}=362$} & Never & Rarely & Occasionally & Regularly & Always & Mean & SD \\
\hline 1 & $\begin{array}{l}\text { How often are appointment cards written in } \\
\text { a way that is easy to read and understand? }\end{array}$ & $25.1 \%$ & $17.1 \%$ & $22.4 \%$ & $13.5 \%$ & $21.8 \%$ & 2.90 & 1.548 \\
\hline 2 & $\begin{array}{l}\text { How often are medical forms difficult to } \\
\text { understand and fill out? }\end{array}$ & $9.7 \%$ & $16.0 \%$ & $31.5 \%$ & $24.0 \%$ & $18.8 \%$ & 3.26 & 1.231 \\
\hline 3 & $\begin{array}{l}\text { How often do you have difficulty } \\
\text { understanding written information } \\
\text { your health care provider gives you? }\end{array}$ & $10.8 \%$ & $21.3 \%$ & $24.3 \%$ & $24.3 \%$ & $19.3 \%$ & 3.20 & 1.274 \\
\hline 4 & $\begin{array}{l}\text { How often do you have problems learning } \\
\text { about your medical condition because of } \\
\text { difficulty in understanding written } \\
\text { information? }\end{array}$ & $6.9 \%$ & $14.4 \%$ & $25.7 \%$ & $29.8 \%$ & $23.2 \%$ & 3.48 & 1.119 \\
\hline 5 & $\begin{array}{l}\text { How often do you have someone (like a } \\
\text { family member, friend, hospital/clinic } \\
\text { worker, or caregiver) help you read } \\
\text { hospital materials? }\end{array}$ & $13.5 \%$ & $17.7 \%$ & $26.7 \%$ & $24.3 \%$ & $18.0 \%$ & 3.15 & 1.288 \\
\hline 6 & $\begin{array}{l}\text { How often are you confident filling out } \\
\text { medical forms by yourself }\end{array}$ & $13.3 \%$ & $17.4 \%$ & $24.3 \%$ & $21.5 \%$ & $23.5 \%$ & 3.25 & 1.343 \\
\hline 7 & $\begin{array}{l}\text { How often are you confident following the } \\
\text { instructions on the label of a medication } \\
\text { bottle/packet? }\end{array}$ & $9.4 \%$ & $22.9 \%$ & $18.8 \%$ & $19.1 \%$ & $29.8 \%$ & 3.37 & 1.363 \\
\hline & Cumulative Mean & & & & & & 3.23 & 1.31 \\
\hline
\end{tabular}


denoting higher literacy levels. The coding for items serial numbers 2 - 5 on whether medical forms were difficult to understand and fill out, difficulty understanding written information given by health care provider, problems learning about respondent's medical condition because of difficulty in understanding written information, and frequency of someone helping with reading hospital materials were revised so that always denotes low health literacy and never for higher literacy levels. The scores for the items on a scale were summed and divided by the number of items in the scale, giving a weighted mean score ranging from 1 - 5. Functional health literacy was subsequently categorized into either inadequate or adequate for scores between 1 to 3.4 and 3.5 to 5 , respectively.

On average, functional health literacy among the respondents in this study was inadequate, with a mean of 3.23 and standard 1.31, as shown in Table 3. Functional health literacy can be depicted as the cognitive capacity to comprehend, interpret and apply written or oral health information so that someone with adequate literacy level would have a better health condition than one with limited literacy level [2]. Unfortunately, inadequate functional health literacy appears to be a widespread problem among patients with chronic health conditions. A study conducted by Bradley [4] shows that in the United Kingdom, the United States, Australia, and Canada, twenty to fifty percent of the population have low functional health literacy, which can have negative effects on an individual's health status [4] [6]. A recent study by Rademakers and Hejimans [2] further revealed that four out of ten Dutch men and women with chronic disease have inadequate functional health literacy.

Regarding the various items of functional health literacy [FHL], respondents scored poorest, a mean of 2.90 when asked to state how often appointment cards were written in a way that is easy to read and understand, with $25 \%$ stating that it had never been easy to read and understand appointment cards. Additionally, about $19 \%$ and $24 \%$ of the respondents believed that medical forms were either always or regularly difficult to understand and fill out. When asked to state how often they had difficulty understanding written information given by their health care providers, a mean of 3.20 was posted, with $43 \%$ of respondents stating they regularly or always have difficulties.

Writing and reading abilities are increasingly becoming very important in today's healthcare environment, where a lot of emphases are put on self-care and home-based care due to the fragile health infrastructure. According to Geboers [15], people with inadequate functional health literacy cannot often read well and know the body, its functioning, and the nature and causes of different types of disease conditions. This compromises their ability to manage their disease [3]. Beyond reading and other communication skills and knowledge of relevant health topics, making sense of health information and the healthcare system also requires numerical skills, such as disease risk or the normal range of values such as blood pressure or cholesterol [16].

In this study, $42 \%$ of the respondents reported that they either regularly or always require someone [like a family member, friend, hospital/clinic worker, or 
caregiver] to help them read hospital materials. Only $14 \%$ could read independently, meaning that most of the respondents were forced to rely on someone else for assistance with their sensitive information. Concerning how often the respondents were confident filling out medical forms by themselves, $14 \%$ and $17 \%$ were either "never" or "rarely" confident in filling out hospital forms. This coupled with the fact that only about $30 \%$ of these respondents were "always" confident following the instructions on the label of a medication bottle/packet, could present a big challenge, especially in a condition like HIV/AIDS that is surrounded by a lot of stigma and discrimination.

Gokengin et al. [17], in their analysis of HIV/AIDS-related stigma and discrimination in Turkey, found out that HIV-related stigma was widespread, originated from close associates of the patient, and with undesired effects. Being gossiped about, being subject to verbal abuse, threats, and injury were the most common forms of stigma. Thirty percent of the participants lost their jobs due to HIV-related stigma, and 20\% were denied healthcare services because of HIV positivity. Perceived HIV-related stigma may make people living with HIV to internalize stigma and anticipate stigmatizing experiences, causing undesired health and psychosocial outcomes [18].

\subsection{Doctor-Patient Communication}

To measure the quality of doctor-patient communication, fifteen questions adapted from the Consumer Assessment of Healthcare Providers and Systems [CAHPS] health literacy item set were used. A five response category comprising "Never," "Rarely," "Occasionally," "Regularly" and "Always" was utilized. For all but two of the CAHPS items, "always" represented the most positive response, but for the questions asking about health providers using medical jargon and speaking too fast, the "never" response represented the highest approval from the patients. Therefore, the coding for these questions was reversed to be consistent with the other CAHPS items. A total weighted mean score was calculated for each CAHPS survey collected, with possible mean scores ranging from 1 - 5, representing the lowest rating provider communication and the highest possible provider communication rating, respectively. Consequently, mean scores below 3.5 were graded as non-effective, while scores ranging from 3.5 to 5 were graded effectively.

Table 4 illustrates that the patients surveyed rated the quality of their provider's communication as effective with a mean score of 3.60 and a standard deviation of 1.164. Effective communication from providers may compensate for a lack of understanding with patients with inadequate health literacy in clinical settings. Burch \& Jackson [19] noted that in the recent past, the average number of clinical items, ranging from diagnoses, medications to diagnostic tests addressed at adult primary care visits, has increased from 5 to 7 , while the time spent on each item has decreased from 4.4 to 3.8 minutes. This underscores how effective communication can be an important tool, especially in resource constraint settings. 
Table 4. Distribution of respondents by the perception of doctor-patient communication.

\begin{tabular}{|c|c|c|c|c|c|c|c|}
\hline $\begin{array}{l}\text { Doctor-Patient Communication (DPC) } \\
\text { Items } \mathrm{N}=362\end{array}$ & Never & Rarely & Occasionally & Regularly & Always. & Mean & SD \\
\hline How often does your doctor listen carefully to you? & $6.1 \%$ & $11.3 \%$ & $35.1 \%$ & $19.9 \%$ & $27.6 \%$ & 3.52 & 1.182 \\
\hline $\begin{array}{l}\text { How often does your doctor explain your health } \\
\text { concerns in a way that is easy to understand? }\end{array}$ & $2.8 \%$ & $14.6 \%$ & $24.9 \%$ & $24.6 \%$ & $33.1 \%$ & 3.71 & 1.154 \\
\hline $\begin{array}{l}\text { How often does your doctor give you easy to } \\
\text { understand instructions about taking care } \\
\text { of your health problems? }\end{array}$ & $4.1 \%$ & $11.6 \%$ & $21.8 \%$ & $32.0 \%$ & $30.4 \%$ & 3.73 & 1.136 \\
\hline $\begin{array}{l}\text { How often does your doctor seem to know the } \\
\text { important information about your health problems? }\end{array}$ & $3.3 \%$ & $9.7 \%$ & $23.5 \%$ & $30.1 \%$ & $33.4 \%$ & 3.81 & 1.105 \\
\hline $\begin{array}{l}\text { How often does your doctor show respect } \\
\text { for what you tell him/her? }\end{array}$ & $2.2 \%$ & $10.8 \%$ & $23.8 \%$ & $24.6 \%$ & $38.7 \%$ & 3.87 & 1.114 \\
\hline $\begin{array}{l}\text { How often does your doctor spend } \\
\text { enough time with you? }\end{array}$ & $3.9 \%$ & $7.5 \%$ & $19.6 \%$ & $29.3 \%$ & $39.8 \%$ & 3.94 & 1.113 \\
\hline $\begin{array}{l}\text { How often does your doctor use medical } \\
\text { words that you do not understand? }\end{array}$ & $16.9 \%$ & $20.4 \%$ & $35.6 \%$ & $18.8 \%$ & $8.3 \%$ & 3.19 & 1.169 \\
\hline $\begin{array}{l}\text { How often does your doctor talk too fast } \\
\text { when talking with you? }\end{array}$ & $16.3 \%$ & $22.4 \%$ & $26.8 \%$ & $22.1 \%$ & $12.4 \%$ & 3.08 & 1.262 \\
\hline $\begin{array}{l}\text { How often does your doctor use pictures or } \\
\text { drawings, or models to explain issues to you? }\end{array}$ & $11.6 \%$ & $18.0 \%$ & $28.7 \%$ & $24.6 \%$ & $17.1 \%$ & 3.18 & 1.244 \\
\hline $\begin{array}{l}\text { How often does your doctor give you easy to } \\
\text { understand instructions about how } \\
\text { to take your medicines? }\end{array}$ & $2.5 \%$ & $11.0 \%$ & $24.6 \%$ & $25.4 \%$ & $36.5 \%$ & 3.82 & 1.117 \\
\hline $\begin{array}{l}\text { How often does your doctor explain the possible } \\
\text { side effects of your medicines? }\end{array}$ & $2.5 \%$ & $12.4 \%$ & $31.2 \%$ & $20.2 \%$ & $33.7 \%$ & 3.7 & 1.133 \\
\hline $\begin{array}{l}\text { How often does your doctor explain medication side } \\
\text { effects in a way that is easy to understand? }\end{array}$ & $4.7 \%$ & $8.8 \%$ & $32.3 \%$ & $24.9 \%$ & $29.3 \%$ & 3.65 & 1.129 \\
\hline $\begin{array}{l}\text { How often does your doctor suggest ways to help } \\
\text { you remember to take your medicines? }\end{array}$ & $4.7 \%$ & $8.8 \%$ & $32.3 \%$ & $24.9 \%$ & $29.3 \%$ & 3.6 & 1.169 \\
\hline $\begin{array}{l}\text { How often does your doctor explain the results of } \\
\text { your blood test, X-ray, or other laboratory tests in a } \\
\text { way that is easy to understand? }\end{array}$ & $5.8 \%$ & $16.6 \%$ & $31.5 \%$ & $21.8 \%$ & $24.3 \%$ & 3.42 & 1.189 \\
\hline $\begin{array}{l}\text { How often do you feel that your doctor cares about } \\
\text { you as a person? }\end{array}$ & $5.0 \%$ & $11.9 \%$ & $19.3 \%$ & $20.7 \%$ & $43.1 \%$ & 3.85 & 1.237 \\
\hline Cumulative mean/SD & & & & & & 3.60 & 1.164 \\
\hline
\end{tabular}

\subsection{Functional Health Literacy and Doctor-Patient Communication}

Simple logistic regression was carried to determine the degree to which functional health literacy influences doctor-patient communication among HIV/AIDS patients in Homa Bay County, Kenya. Before conducting logistic regression analysis, data for doctor-patient communication was transformed into a binary form assuming 0 and 1 values to mean non-effective and effective, respectively. The overall effectiveness of the dependent variable was measured using the fifteen 
items on the questionnaire. To classify the dependent variable [Doctor-Patient communication, DCP] as effective or non-effective, the weighted scale of the indicator variables forming the dependent variables was computed as follows:

$$
\mathrm{Y}=\frac{\mathrm{DCP}(1)+\mathrm{DCP}(2)+\cdots+\mathrm{DCP} 15(15)}{1+2+\cdots 15}
$$

$\mathrm{Y}$ (doctor-patient communication among HIV/AIDS patients) was a continuous random variable with values lying between $0-5$. The $\mathrm{Y}$ values were further transformed into two categories with values of lying between $1-3.4$ were categorized as non-effective while any value of Y lying between 3.5 - 5.0 was categorized as effective. From the above description, new $\mathrm{Y}$ values were corded as effective [1] and non-effective [0], respectively, before conducting logistic regression.

As displayed in Block 0 Table 5, the output as per classification table 1 in the absence of predictor variable [functional health literacy] suggests that $74.3 .0 \%$ of the respondents believed that doctor-patient communication among HIV/AIDS patients in Homa Bay county was effective. Variables in the equation table also illustrate the predicted odds of $[\operatorname{Exp}(B)]=2.892$, as shown below.

\section{Block 0: Beginning Block}

Table 5. Classification table 1 for functional health literacy.

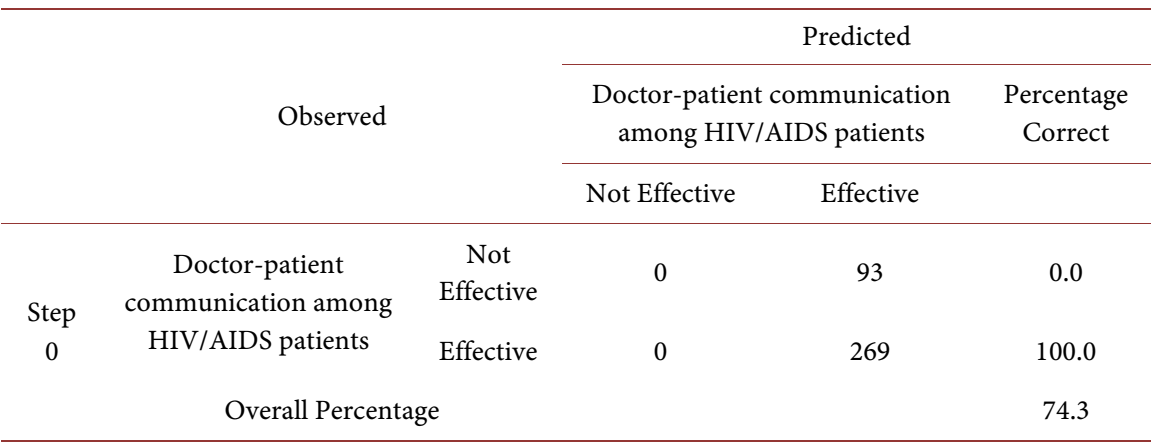

a. Constant is included in the model. b. The cut value is 0.500 .

\subsection{Variables in the Equation for Functional Health Literacy}

To obtain a detailed Block 1 output, the explanatory variable [functional health literacy] was included in the model under two main categories, initially in a model without a moderator and when the model had a moderator, in this case, patients' demographic factors. $P$ values of less than 0.05 were used to assess the presence of significant improvement from Block 0 results.

\begin{tabular}{|c|c|c|c|c|c|c|c|}
\hline & & B & S.E. & Wald & $\mathrm{df}$ & Sig. & $\operatorname{Exp}(B)$ \\
\hline $\begin{array}{c}\text { Step } \\
0\end{array}$ & Constant & 1.06194 & 0.117 & 82.149 & 1 & 0.000 & 2.892 \\
\hline
\end{tabular}

The results as presented in the omnibus test output (Table 6) for both model 1 and 2 without a moderator and with a moderator respectively demonstrate that 
models were significant from block 0 model since both recorded p-values of $0.000<0.05$, indicating that functional health literacy had a significant positive influence on doctor-patient communication among HIV/AIDS patients in Homa Bay county both in circumstances where moderator was included and where the moderator was not included. Cox \& Snell and Nagelkerke R-square values further demonstrated that between $25.0 \%$ and $31.8 \%$ of the variation in doctor-patient communication among HIV/AIDS patients in Homa Bay county was explained by functional health literacy for the model in block 1 in the absence of moderator and in the presence of moderator [demographic factors] respectively.

Classification table 2 (Table 7) for functional health literacy further underscores the importance of patients' demographic factors (moderator) in doctor-patient communication as there was a superior increase in classification rate. The table indicates an improvement of both models in block one as the classification rate increased by $2.2 \%$ to $76.5 \%$, up from 74.3 in Block 0 for model 1 [absent of moderator], and by $4.2 \%$ to $78.5 \%$ in the presence of the moderator.

Similarly, based on variables in the equation table 2 after inclusion of functional health literacy in the block, the relationship between functional health literacy and doctor-patient communication among HIV/AIDS patients given by logistic regression equations can be expressed as $\mathrm{Y}=-6.234+1.981 \mathrm{X}_{1}$ for the model without moderator and $\mathrm{Y}=-9.846+0.991 \mathrm{X}_{1}+2.294 \mathrm{X}_{1} \times \mathrm{Z}$ for the model with the moderator. This can be interpreted that for every unit of functional health literacy, the value of doctor-patient communication among HIV/AIDS patients in Homa Bay county changed by 1.981in the absence of a moderator and 2.294 when demographic factors were included as a moderator.

Finally, to ascertain the goodness of fit based on the logistic regression model,

Table 6. Omnibus tests of model coefficients for functional health literacy.

\begin{tabular}{|c|c|c|c|c|}
\hline Model 1 & (Absence of Moderator) & Chi-square & df & Sig. \\
\hline \multirow{3}{*}{ Step 1} & Step & 71.784 & 1 & 0.000 \\
\hline & Block & 71.784 & 1 & 0.000 \\
\hline & Model & 71.784 & 1 & 0.000 \\
\hline \multirow[t]{2}{*}{ Model 2} & (Presence of Moderator) & Chi-square & $\mathrm{df}$ & Sig. \\
\hline & Step & 93.695 & 2 & 0.000 \\
\hline \multirow[t]{2}{*}{ Step 1} & Block & 93.695 & 2 & 0.000 \\
\hline & Model & 93.695 & 2 & 0.000 \\
\hline \multicolumn{5}{|c|}{ Model Summary for Functional health literacy } \\
\hline Step & -2 Log likelihood & \multicolumn{2}{|c|}{ Cox \& Snell R Square } & Nagelkerke R Square \\
\hline 1 & $366.557^{\mathrm{a}}$ & \multicolumn{2}{|c|}{0.171} & 0.250 \\
\hline 2 & $344.646^{\mathrm{a}}$ & \multicolumn{2}{|c|}{0.217} & 0.318 \\
\hline
\end{tabular}

a. Estimation terminated at iteration number 4 because parameter estimates changed by less than 0.001 . 
Table 7. Classification table 2 for functional health literacy.

\begin{tabular}{|c|c|c|c|c|c|}
\hline \multicolumn{6}{|c|}{ Model 1 Without a moderator } \\
\hline & \multirow{3}{*}{\multicolumn{2}{|c|}{ Observed }} & \multicolumn{3}{|c|}{ Predicted } \\
\hline & & & \multicolumn{2}{|c|}{$\begin{array}{l}\text { Doctor-patient communication } \\
\text { among HIV/AIDS patients }\end{array}$} & \multirow[t]{2}{*}{$\begin{array}{l}\text { Percentage } \\
\text { Correct }\end{array}$} \\
\hline & & & Not Effective & Effective & \\
\hline \multirow{7}{*}{ Step 0} & $\begin{array}{l}\text { Doctor-patient } \\
\text { communication }\end{array}$ & $\begin{array}{c}\text { Not } \\
\text { Effective }\end{array}$ & 22 & 71 & 23.6 \\
\hline & patients & Effective & 14 & 255 & 94.8 \\
\hline & \multicolumn{2}{|c|}{ Overall Percentage } & & & 76.5 \\
\hline & \multicolumn{4}{|c|}{ Model 2 With moderator } & \\
\hline & \multirow{3}{*}{\multicolumn{2}{|c|}{ Observed }} & \multicolumn{3}{|c|}{ Predicted } \\
\hline & & & \multicolumn{2}{|c|}{$\begin{array}{l}\text { Doctor-patient communication } \\
\text { among HIV/AIDS patients }\end{array}$} & $\begin{array}{c}\text { Percentage } \\
\text { Correct }\end{array}$ \\
\hline & & & Not Effective & Effective & \\
\hline \multirow{3}{*}{ Step 0} & $\begin{array}{l}\text { Doctor-patient } \\
\text { communication }\end{array}$ & $\begin{array}{l}\text { Not } \\
\text { Effective }\end{array}$ & 36 & 57 & 38.7 \\
\hline & $\begin{array}{l}\text { among } \\
\text { patients }\end{array}$ & Effective & 22 & 248 & 92.2 \\
\hline & \multicolumn{2}{|c|}{ Overall Percentage } & & & 78.5 \\
\hline
\end{tabular}

a. Constant is included in the model. b. The cut value is 0.500 .

the Hosmer and Lemeshow test, which is a Chi-square test statistic used to check if the logistic regression model is suitable for a given data set, was applied. As indicated in Table 8 , the models were good since the p-values established were much greater than the conventional p-value of 0.05 , at 0.931 , and 0.983 for models 1 and 2, respectively. This further illustrated that functional health literacy significantly influenced doctor-patient communication among HIV/AIDS patients in Homa Bay County, Kenya.

As narrated above, functional health literacy positively influences doctor patient's communication in this study. Indeed, every unit of functional health literacy increased the value of doctor-patient communication among HIV/AIDS patients in Homa Bay county by up to 2.294. This finding is in line with previous studies, which have also found an association between functional health literacy and health outcomes [20] [21]. In contrast, a study by Barbers et al. [22] on the role of health literacy in patients' involvement in medical decision-making did not find a relationship between most aspects of health literacy and involvement in medical decision-making. The above study was conducted among the general population and also used five scales of the Health Literacy Questionnaire [HLQ] as opposed to the seven [7] items scale used in this study. The variation in the findings of various studies may also be due to many tools currently being used to measure functional health literacy. 
Table 8. Variables equation table.

\begin{tabular}{|c|c|c|c|c|c|c|c|}
\hline \multicolumn{8}{|c|}{ Model 2 Without a moderator } \\
\hline & & B & S.E. & Wald & $\mathrm{df}$ & Sig. & $\operatorname{Exp}(B)$ \\
\hline \multirow[t]{2}{*}{ Step $1^{a}$} & $\begin{array}{c}\text { Functional health } \\
\text { literacy }\end{array}$ & 1.981 & 0.288 & 47.377 & 1 & 0.000 & 7.253 \\
\hline & Constant & -6.234 & 1.032 & 36.450 & 1 & 0.000 & 0.002 \\
\hline \multicolumn{8}{|c|}{ Model 1 With moderator } \\
\hline & & B & S.E. & Wald & $\mathrm{df}$ & Sig. & $\operatorname{Exp}(B)$ \\
\hline \multirow{3}{*}{ Step $1^{\mathrm{a}}$} & $\begin{array}{c}\text { Functional health } \\
\text { literacy }\end{array}$ & 0.991 & 0.344 & 8.278 & 1 & 0.004 & 2.694 \\
\hline & $\begin{array}{c}\text { Functional health } \\
\text { literacy } \mathrm{Z}\end{array}$ & 2.294 & 0.512 & 20.047 & 1 & 0.000 & 9.919 \\
\hline & Constant & -9.846 & 1.388 & 50.332 & 1 & 0.000 & 0.000 \\
\hline
\end{tabular}

a. Variable(s) entered on step 1: $\mathrm{X}_{4}$.

\section{Conclusion}

Functional health literacy is an important driver for positive patient outcomes. However, this study found that the level of functional health literacy among the study respondents was inadequate. This is particularly unfortunate since this study also established that functional health literacy has a significant positive influence on doctor-patient communication. There is, therefore need to document the determinants of functional health literacy to improve it and make doctor-patient interaction an enjoyable and meaningful experience.

\section{Conflicts of Interest}

The authors declare no conflicts of interest regarding the publication of this paper.

\section{References}

[1] Horning, A. (2019) Developing Information Literacy through Critical Reading and Writing. In: Lamb, M.R. and Parrott, J., Eds., Digital Reading and Writing in Composition Studies, Routledge, New York, 41-56.

https://doi.org/10.4324/9781351052948-3

[2] Rademakers, J. and Heijmans, M. (2018) Beyond Reading and Understanding: Health Literacy as the Capacity to Act. International Journal of Environmental Research and Public Health, 15, 1676. https://doi.org/10.3390/ijerph15081676

[3] Paasche-Orlow, M.K. and Wolf, M.S. (2016) The Causal Pathways Linking Health Literacy to Health Outcomes. American Journal of Health Behavior, 31, 19-26. https://doi.org/10.5993/AJHB.31.s1.4

[4] Disler, R., Glenister, K. and Wright, J. (2020) Rural Chronic Disease Research Patterns in the United Kingdom, United States, Canada, Australia and New Zealand: A Systematic Integrative Review. BMC Public Health, 20, Article No. 770. https://doi.org/10.1186/s12889-020-08912-1

[5] Bradley, C. (2013) Information Literacy in the Programmatic University Accreditation Standards of Select Professions in Canada, the United States, the United King- 
dom, and Australia. Journal of Information Literacy, 7, 44-68. https://doi.org/10.11645/7.1.1785

[6] Ishikawa, H., Takeuchi, T. and Yano, E. (2008) Health Literacy Scales. PsycTESTS Dataset. https://doi.org/10.1037/t17922-000

[7] Nutbeam, D. (2015) Defining, Measuring and Improving Health Literacy, (August).

[8] Liu, H., Zeng, H., Shen, Y., Zhang, F., Sharma, M., Lai, W., Zhao, Y., et al. (2018) Assessment Tools for Health Literacy among the General Population: A Systematic Review. International Journal of Environmental Research and Public Health, 15, 1711. https://doi.org/10.3390/ijerph15081711

[9] Mehzabin, R., Hossain, K.J., Moniruzzaman, M. and Sayeed, S.K.J.B. (2019) Association of Functional Health Literacy with Glycemic Control: A Cross-Sectional Study in Urban Population of Bangladesh. Journal of Medicine, 20, 19-24. https://doi.org/10.3329/jom.v20i1.38816

[10] Lai, A.Y., Ishikawa, H., Kiuchi, T., Mooppil, N. and Griva, K. (2013) Communicative and Critical Health Literacy, and Self-Management Behaviors in End-Stage Renal Disease Patients with Diabetes on Hemodialysis. Patient Education and Counseling, 91, 221-227. https://doi.org/10.1016/j.pec.2012.12.018

[11] An, S. and Muturi, N. (2011) Subjective Health Literacy and Older Adults' Assessment of Direct-to-Consumer Prescription Drug Ads. Journal of Health Communication, 16, 242-255. https://doi.org/10.1080/10810730.2011.604387

[12] Ngetich, A. (2018) Community Acceptability of Voluntary Medical Male Circumcision (VMMC) as a Strategy in the Fight against the Spread of HIV and AIDS among Residents of Homa-Bay County Kenya. Texila International Journal of Public Health, 6, 16-24. https://doi.org/10.21522/tijph.2013.06.03.art002

[13] Kimanga, D.O., Ogola, S., Umuro, M., Ng'ang'a, A., Kimondo, L., Murithi, P., Muttunga, J., Waruiru, W., Mohammed, I., Sharrif, S., De Cock, K.M. and Kim, A.A. (2014) Prevalence and Incidence of HIV Infection, Trends, and Risk Factors among Persons Aged 15-64 Years in Kenya. JAIDS Journal of Acquired Immune Deficiency Syndromes, 66, S13-S26. https://doi.org/10.1097/QAI.0000000000000124

[14] Fagbamigbe, A.F., Adebayo, S.B. and Idemudia, E. (2016) Marital Status and HIV Prevalence among Women in Nigeria: Ingredients for Evidence-Based Programming. International Journal of Infectious Diseases, 48, 57-63. https://doi.org/10.1016/j.ijid.2016.05.002

[15] Geboers, B. (2017) Understanding the Role of Health Literacy in Self-Management and Health Behaviors among Older Adults.

[16] Griffey, R.T., McNaughton, C.D., McCarthy, D.M., Shelton, E., Castaneda-Guarderas, A., Young-Brinn, A., Grudszen, C., et al. (2016) Shared Decision Making in the Emergency Department among Patients with Limited Health Literacy: Beyond Slower and Louder. Academic Emergency Medicine, 23, 1403-1409.

https://doi.org/10.1111/acem.13104

[17] Gokengin, D., Calik, S. and Oktem, P. (2017) Analysis of HIV/AIDS-Related Stigma and Discrimination in Turkey: Results of the People Living with HIV Stigma Index. Klimik Dergisi/ Klimik Journal, 30, 15-21. https://doi.org/10.5152/kd.2017.03

[18] Ibrahim, K., Kombong, R. and Sriati, A. (2019) The Difference of Perceived HIV Stigma between People Living with HIV Infection and Their Families. Nurse Media Journal of Nursing, 9, 117-127. https://doi.org/10.14710/nmjn.v9i2.24256

[19] Burch, J. and Jackson, C. (2019) How Do Point-of-Care Diagnostic Tests for Acute Respiratory Infection Affect Antibiotic Prescribing Behavior in Primary Care? Cochrane Clinical Answers. https://doi.org/10.1002/cca.2434 
[20] Muscat, D.M., Morony, S., Shepherd, H.L., Smith, S.K., Dhillon, H.M., Trevena, L., Hayen, A., Luxford, K., Nutbeam, D. and McCaffery, K. (2015) Development and Field Testing of a Consumer Shared Decision-Making Training Program for Adults with Low Literacy. Patient Education and Counseling, 98, 1180-1188. https://doi.org/10.1016/j.pec.2015.07.023

[21] Tolan, N.V. (2020) Health Literacy and the Desire to Manage One's Own Health. Clinics in Laboratory Medicine, 40, 1-12. https://doi.org/10.1016/j.cll.2019.11.007

[22] Brabers, A.E., Rademakers, J.J., Groenewegen, P.P., Van Dijk, L. and De Jong, J.D. (2017) What Role Does Health Literacy Play in Patients' Involvement in Medical Decision-Making? PLoS ONE, 12, e0173316.

https://doi.org/10.1371/journal.pone.0173316 